\title{
$\because$ Understanding and intervening with the total population of smokers
}

The article by Kaplan and colleagues on the stages of smoking cessation, which discusses the results of the 1990 California Tobacco Survey in this issue of Tobacco Control (pp 139-44), reflects the increasing sophistication in our knowledge of smokers and smoking. This particular study is impressive in that it combines size, representativeness of a defined population, and an extensive, detailed set of questions focusing on smoking. The focus of the article is on the stages of change, a series of discrete stages which indicate an individual's readiness to quit and progress in quitting. The five steps are precontemplation, contemplation, preparation, action, and maintenance. Although the data are restricted to a single state, California is an interesting sample due to its very aggressive smoking control programme. Even with such a programme, however, less than $20 \%$ of the current smokers are in the preparation stage of change (ie, ready to take action to stop smoking), and over $35 \%$ are in "precontemplation," with no intention of stopping in the near future. A recent prevalence survey in South Australia demonstrated a similar but slightly different distribution of smokers, with $24 \%$ in precontemplation, $47 \%$ in contemplation, and $29 \%$ in preparation. ${ }^{1}$ Stage distributions reported in the California survey parallel a recent report from a randomdigit-dial telephone survey sample in Rhode Island, USA, with $42 \%$ of the smokers in precontemplation, $40 \%$ in contemplation, and $18 \%$ in preparation. ${ }^{2}$ However, if one examines specific sub-populations, the distribution of smokers across stages can be significantly different from the total population. For example, in a female sample from a California health maintenance organisation, a larger percentage were in the precontemplation stage (47\%) and slightly fewer were in the preparation stage $(20 \%) .^{3}$ The paper by Kaplan and colleagues also demonstrates differences in distributions for different subgroups. These reports demonstrate that there are remarkable similarities and important differences in these various populations and subpopulations of smokers. Using the stages of change perspective, researchers are gaining a more defined and refined picture of smokers with respect to their readiness to stop smoking and their progress on the road to successfully maintained cessation.

There are several important implications of this more sophisticated view of smokers. Firstly, such a view as provided in the California survey can provide the backdrop for any assessment and recruitment efforts related to smoking control in that state. Secondly, intervention efforts can be targeted to specific stage subgroups of the population of smokers. Thirdly, evaluations of smoking control efforts can more sensitively assess the impact of interventions not only on cessation but also on the progression between stages and the percentages of smokers in each stage.

Smoking control efforts in California can be more sensitively directed as a result of this survey. As has already been done, researchers can compare their samples of smokers at worksites, health facilities, or neighbourhoods to the population base rates in order to understand better the uniqueness of their target population. ${ }^{3}$ For example, the data in the California survey show a significantly greater percentage of Hispanics and AfricanAmericans in the preparation stage of change; this has clear implications for researchers and interventionists in these communities.

The clearest and probably most important benefit of this better understanding of smokers' readiness to change relates to intervention. Interventions in the area of smoking cessation generally are one of two types: (1) reactively recruited samples, ie, individuals who respond to recruitment notices, and (2) low-cost interventions designed to reach a large proportion of the population. We will refer to the former as "individual intervention" and the latter as "public health" interventions. The individual intervention typically has a relatively high efficacy - rates of $30 \%$ to $40 \%$ point prevalence cessation have been reported but reach a relatively small proportion of a defined population - typically less than 5\%. Public health interventions, such as media campaigns, often reach a relatively large proportion of the population but have a relatively low efficacy.

A useful way of conceptualising an intervention is to refer to its impact. Impact is the efficacy of an intervention multiplied by the recruitment rate. ${ }^{2,5}$ For example, if an individual intervention had a high efficacy $(40 \%)$ but reaches only $5 \%$ of the population, the impact will be low $($ Impact $=0.02)$. In contrast, a public health intervention that reaches a larger proportion of the population $(80 \%)$ but has a low efficacy (0.04) can still have a higher impact (Impact $=0.032$ ). The ideal would be to design interventions which have a high efficacy (say, $20 \%$ ) but which can be employed with a high proportion of the population (say, $70 \%$ ); this would result in a high impact (Impact $=$ 0.14). In other words, we need to somehow combine the strengths of the individual intervention and the reach of the public health intervention.

It is clear from the California and Rhode Island samples that we can expect to find that approximately $40 \%$ of the smokers are in the precontemplation stage, $40 \%$ are in the contemplation stage, and $20 \%$ are in the preparation stage. However, the majority of our interventions, both individual and public health, are designed for those people ready to stop smoking, ie, people in the preparation stage. This result explains why both approaches have had relatively low impacts. In the individual approach, reactive recruitment results in self-selection, ie, individuals must decide to be exposed to the intervention. Samples will consist of a disproportionate number of people in the preparation stage. People in the earlier stages find that the intervention is not appropriate for them and either do not volunteer or quickly drop-out. On the other hand, the efficacy of the treatment is high because it is now matched to the self-selected sample. In a public health approach, the intervention reaches a much larger proportion of the population. However, most interventions are cessationoriented, such as media campaigns or increased taxation, and are not appropriate for the vast majority of smokers who are not ready to stop smoking. These people simply ignore the mis-matched interventions, resulting in a low efficacy. In some cases, the intervention may produce an unintended negative reaction.

Both individual and public health approaches can be used to target smokers in specific stages. We have found that the most effective interventions are matched to the stage of the smoker. We can think of a series of four transitions and design interventions appropriate for each. The transitions are: (1) from precontemplation to contemplation; (2) from contemplation to preparation; (3) from preparation to action; and (4) from action to maintenance. The vast majority of previous interventions have focused on a single transition, from preparation to 
action. Recently, concern with relapse prevention has focused attention on the transition from action to maintenance. ${ }^{6-8}$ Very little research has focused on the first two transitions.

Finally, evaluations of all types of interventions for smoking control could benefit from the perspective offered by the stages of change. These stages not only represent steps on the road to successful cessation but a series of tasks that need to be accomplished. There is also a set of outcome measures that have been shown to be sensitive to progress for each of the four transitions.

The stages of change is the central organising construct of the Transtheoretical Model..$^{9,10}$ The model also describes a set of dependent measures, including Decisional Balance, Temptation, Self-efficacy, and specific target behaviours for smoking cessation. ${ }^{11-14}$ Highly reliable measures have been developed for each of these key constructs in the area of smoking cessation. The use of this complete set of dependent measures would greatly increase our sensitivity to change. In addition, the Transtheoretical model describes a set of independent variables, the processes of change, which can guide the design of interventions. ${ }^{14}$ The relationships between the stages and the processes, and between the stages and the dependent measures, have been established in both cross-sectional and longitudinal analyses, across many different samples.

A number of interventions are now under development which focus on matching the intervention to subjects'

1 Owen N, Wakefield M, Roberts L, Esterman A. Stages of readiness to quit smoking: population prevalence and correlates. Health Psychol 1992; 11 413-7.

2 Velicer WF, Fava JL, Prochaska JO, Rossi JS, Abrams DB, Goldstein MG et al. Design for a small state. Paper presented at the society of Behavioral Medicine Meeting, San Francisco, March, 1983.

3 Gritz ER, Berman BA, Bastani R, Wu M. A randomized trial of a self help smoking cessation intervention in a non-volunteer female population: testing the limits of the public health model. Health Psychol 1992; 11: $280-9$.

4 Schmidt TL, Jeffery RW, Hellerstedt WL. Direct mail recruitment to house-based smoking and weight control programs: a comparison of house-based smoking and weight cont

5 Velicer WF, Rossi JS, Ruggiero L, Prochaska JO. Minimal interventions appropriate for an entire population of smokers. In: Richmond R, ed, Interventions for smokers: an international perspective. Baltimore: Williams \& Wilkins, in press.

6 Brownell KD, Marlatt CA, Lichenstein E, Wilson CT. Understanding and preventing relapse. Am Psychol 1986; 41: 765-82.

7 Cummings C, Gordon JR, Marlatt GA. Relapse: prevention and prediction. In: Miller WR, ed, The addictive behaviors Oxford: Pergamon, 1980 291-322.

8 Marlatt GA, Gordon JR. Determinants of relapse: implications for the maintenance of behavior change. In: Davidson P, Davidson S, eds Behavioral medicine: changing health lifestyles New York: Brunner/ Mazel, 1980: 410-52.

9 Prochaska JO, DiClemente CC. Stages and processes of self-change of smoking: toward an integrative model of change. $\mathcal{F}$ Consul Clin Psychol smoking: toward

10 Prochaska JO, DiClemente CC. Toward a comprehensive model of change. In: Miller W, Heather N, eds, Addictive behaviors: processes of change. New York: Academic Press, 1986. stage of change and are designed for use with a whole population. Examples include: manuals and other written materials, telephone counsellor calls, expert system interventions, and interventions with physicians. The Transtheoretical model in general and stages of change in particular can be used to guide the interventions. For example, a series of manuals, each with stage-specific materials, have been shown to be more effective than a single manual. ${ }^{5,16}$ A series of telephone counsellor calls, initiated by the counsellor rather than the smoker, has also proven to be an effective intervention. ${ }^{5,16,17}$ An expert system is a computer-based intervention which combines assessment and intervention and permits the development of completely individualised interventions. ${ }^{5,16,18} \mathrm{~A}$ physician intervention focuses on changing physician intervention and would be more difficult to initiate but has the potential of being self-maintaining. ${ }^{2,19}$ Each of these four interventions has the potential of combining the individualisation and intensity of the individual intervention and the high participation rates of the public health approach to result in high-impact interventions. ${ }^{20}$

Cancer Prevention Research Consortium

WAYNE F VELICER

University of Rhode Island,

Kingston, Rhode Island 02881, USA

University of Houston,

CARLO C DiCLEMENTE

Houston, Texas, USA

11 DiClemente CC, Prochaska JO, Gilbertini M. Self-efficacy and the stages of self-change. Cognitive Ther 1985; 9: 181-200.

12 Velicer WF, DiClemente CC, Prochaska JO, Brandenburg N. Decisional balance measure for assessing and predicting smoking status. F Pers Soc Psychol 1985; 48: 1279-89.

13 Velicer WF, Prochaska JO, Rossi JS, Snow MG. Assessing outcome in smoking cessation studies. Psychol Bull 1992; 111: 23-41.

14 Prochaska JO, Velicer WF, DiClemente CC, Fava JL. Measuring the processes of change: applications to the cessation of smoking. 7 Consult Clin Psychol 1988; 56:520-8.

15 Prochaska JO, Velicer WF, DiClemente CC, Guadagnoli E, Rossi JS. Patterns of change: dynamic typology applied to smoking cessation. Patterns of change: dynamic typology applied

16 Prochaska JO, DiClemente CC, Velicer WF, Rossi JS. Standardized, individualized, interactive, and personalized self-help programs for individualized, interactive, and personalized
smoking cessation. Health Psychol in press.

17 Thu SH, Pierce J. Telephone counseling for smoking cessation: a randomized trial. Paper presented at Society of Behavioral Medicine Meeting, San Francisco, March, 1993.

18 Velicer WF, Prochaska JO, Bellis JM, DiClemente CC, Rossi JS, Fava JL et al. An expert system intervention for smoking cessation. Addict Behav 1993; 18: 269-90.

19 Richmond R, Webster L, Elkins L, Mendelsohm C, Rollnick S. Smokescreen for the 1990s: A stop smoking program for general practitioners to use with smokers. NSW: Department of Health, 1992.

20 Abrams DB, Emmons KM, Niaura RG, Goldstein MG, Sherman CE. Tobacco dependence: an integration of individual and public health perspectives. In: Nathan DH, Langenbucher JW, McCrady BS perspectives. In: Nathan DH, Langenbucher JW, McCrady BS,
Frankenstein W, eds. Annual Review of Addictions Treatment and Frankenstein W, eds. Annual Review of Addictions Treatment
Research (Vol. 1). New York: Pergamon Press, 1992: 391-436. 